Cite this: Chem. Commun., 2014, 50,2265

Received 8th November 2013, Accepted 11th December 2013

DOI: $10.1039 / c 3 c c 48541 b$

www.rsc.org/chemcomm

\section{Homologous size-extension of hybrid vanadate capsules - solid state structures, solution stability and surface deposition $\dagger$}

\author{
Mariyatra B. Mahimaidoss, ${ }^{a}$ Sergey A. Krasnikov, ${ }^{b}$ Lukas Reck, ${ }^{a}$ Camelia I. Onet, ${ }^{a}$ \\ John M. Breen, ${ }^{a}$ Nianyong Zhu, ${ }^{a}$ Bartosz Marzec, ${ }^{a}$ Igor V. Shvets ${ }^{b}$ and \\ Wolfgang Schmitt*a
}

The dimensions and cavity sizes of the molecular capsules with the general formula $\left[\mathrm{V}_{10} \mathrm{O}_{18} \mathrm{~L}_{4}\right]^{10-}$ can be controlled modularly through the nature of the bifunctional, rigid organophosphonate ligands $L^{1}$ and $L^{2}$ $\left(L^{1}=\right.$ bis(4-phosphonatophenyl)ethyne and $L^{2}=$ bis(4-phosphonatophenyl)butadiyne); the solution stability of the molecular entities as demonstrated by ESI-MS studies permits their assembly on the Au(111) surface on a sub-monolayer scale giving rise to a 2D supramolecular structure that is comparable to the packing arrangements of the capsules in the crystal structures.

The synthesis and characterisation of metallo-supramolecular cages and molecular capsules have received significant scientific attention., In the last few decades preparative efforts were directed towards the synthesis of new cage topologies or homologous species with controllable inner cavities whose chemical, geometrical and electronic attributes may give rise to unique properties that can be exploited in homogeneous catalytic processes, size- and shape-restrictive chemical transformations, separations, drug delivery and sensing devices. ${ }^{2,3}$ Importantly, for the majority of these and other advanced applications, the stability of the assembled molecular species in solution is a key requirement. The development of homologous hollow molecular entities with controllable outer and inner dimensions and chemical attributes relies on the identification of geometrically suitable, kinetically-stable building units with ligand-accessible coordination sites allowing the assembly of the cage entities. ${ }^{4}$ Previously we reported tetranuclear and pentanuclear organophosphonate and -arsonate stabilised vanadate species whose assembly into molecular capsules and cages can be directed through the use of suitable organic ligands or anion-templates. ${ }^{5}$ Here we demonstrate that the dimensions of the molecular capsules with the general formula $\left[\mathrm{V}_{10} \mathrm{O}_{18} \mathrm{~L}_{4}\right]^{10-}$ can modularly be controlled through the extent and the nature of the

\footnotetext{
${ }^{a}$ School of Chemistry \& CRANN, University of Dublin, Trinity College, Dublin 2, Ireland. E-mail: schmittw@tcd.ie; Tel: +353-1-896-3495

${ }^{b}$ School of Physics \& CRANN, University of Dublin, Trinity College, Dublin 2, Ireland $\dagger$ Electronic supplementary information (ESI) available: Synthetic details, additional figures, ESI-MS analysis, crystallographic table and data in CIF format. CCDC 970548 and 970549. For ESI and crystallographic data in CIF or other electronic format see DOI: 10.1039/c3cc48541b
}

bifunctional, rigid organophosphonate ligands $\mathrm{L}^{1}$ and $\mathrm{L}^{2}$ (Fig. 1). We highlight the solution stability of this class of compounds and demonstrate that individual cluster entities can be deposited on the $\mathrm{Au}(111)$ surface and imaged using a scanning tunneling microscope (STM).

Polyoxometalates constitute an interesting class of compounds for the preparation of cages. ${ }^{6}$ The chemistry of polyoxovanadates in aqueous reaction systems as developed by Müller, Zubieta and others is characterised by condensation reactions whereby $\mathrm{V}^{\mathrm{IV}}$ and to a certain extent $\mathrm{V}^{\mathrm{V}}$ species in predominantly square pyramidal coordination environments aggregate to form oligonuclear and polynuclear clusters. ${ }^{7}$

The geometrical restraints associated with the square pyramidal $\left\{\mathrm{O}=\mathrm{VO}_{4}\right\}$ building unit often lead to convex oligonuclear species a)

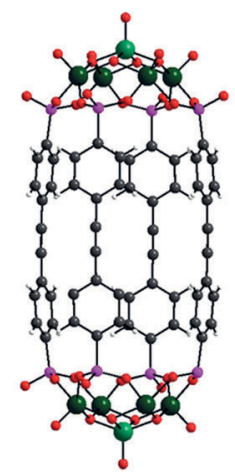

c)

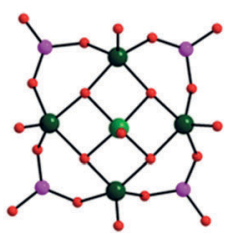

b)

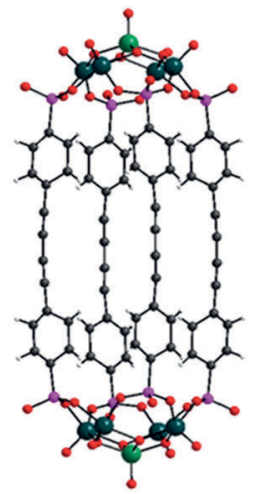

d)

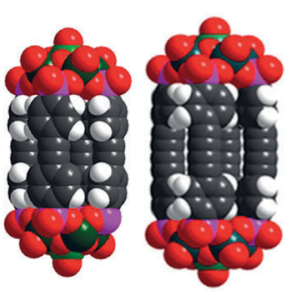

Fig. 1 (a) Crystal structure of $\left[\mathrm{V}_{10} \mathrm{O}_{18} \mathrm{~L}_{4}{ }_{4}\right]^{10-}\left(\mathrm{L}^{1}=1,1^{\prime}\right.$-(1,2-ethynyl)diphenyl-4,4'-bisphosphonate); (b) crystal structure of $\left[\mathrm{V}_{10} \mathrm{O}_{18} \mathrm{~L}^{2}{ }_{4}\right]^{10-}$ $\left(L^{2}=1,1^{\prime}-(1,2,3,4\right.$-diethynyl)diphenyl-4,4'-bisphosphonate); (c) structure of the mixed-valent $\left\{\mathrm{V}_{5} \mathrm{O}_{9}\right\}$ building unit that is stabilised by four fully deprotonated organophosphonate moieties; (d) space filling models of 1 and $\mathbf{2}\left[\mathrm{V}^{\vee}\right.$ light green, $\mathrm{V}^{\mathrm{V}}$ darker green, $\mathrm{P}$ pink, $\mathrm{C}$ grey, $\mathrm{O}$ red]. 


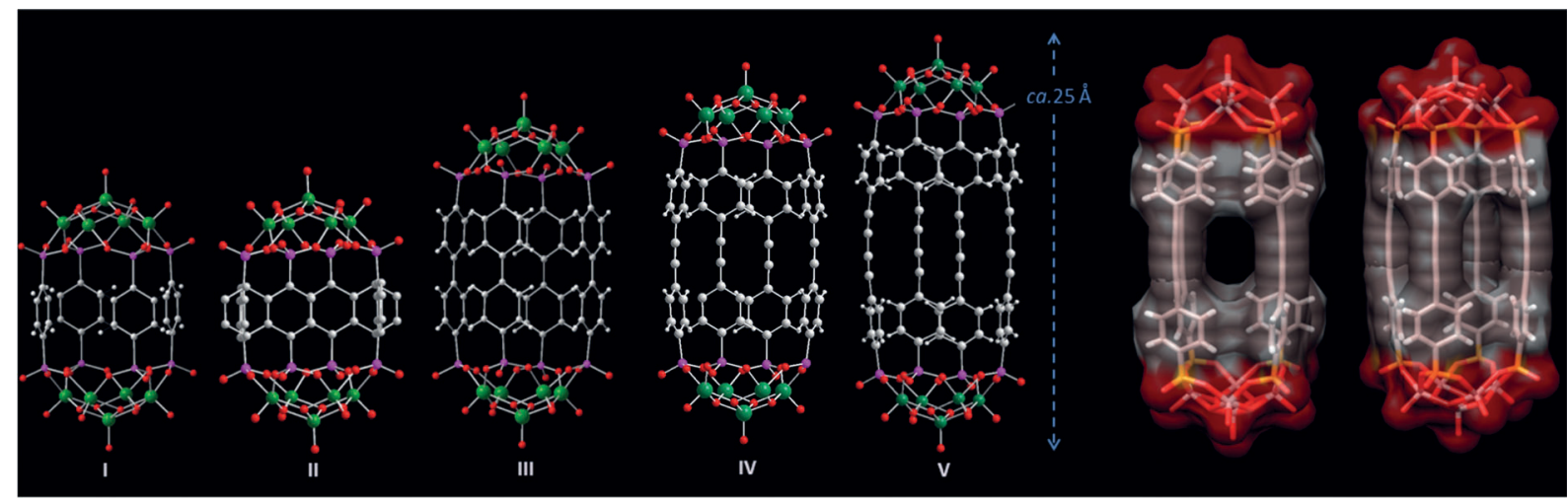

Fig. 2 (I-V) Size comparison of $\left[\mathrm{V}_{10} \mathrm{O}_{18} \mathrm{~L}_{4}\right]^{10-}$ complexes containing benzenediphosphonate (I), naphthalene diphosphonate (II), biphenyl diphosphonate (III), $\mathrm{L}^{1}(\mathrm{IV})$ and $\mathrm{L}^{2}(\mathrm{~V})$ as stabilising ligands. Right: space filling model for $\left[\mathrm{V}_{10} \mathrm{O}_{18} \mathrm{~L}^{2}{ }_{4}\right]^{10-}$ highlighting that the acetylene-based ligands give rise to small openings.

that further condense to form hollow metallo-supramolecular assemblies, in which anions and other nucleophiles may act as templating agents giving rise to distinct topologies. ${ }^{8}$ It has been shown that these assembly principles apply to pure inorganic vanadates as well as hybrid systems that contain organophosphonate and -arsonate ligands. ${ }^{79}$ Of particular interest is a mixed-valent $\left\{\mathrm{V}_{5} \mathrm{O}_{9}\right\}$ unit that forms upon partial reduction of $\mathrm{V}^{\mathrm{V}}$ salts in the presence of suitable organic ligands. In this unit a central $\mathrm{V}^{\mathrm{V}}$ ion is linked via four $\mu_{3}-\mathrm{O}^{2-}$ ligands to four $\mathrm{V}^{\mathrm{IV}}$ centres to form a convex square unit in which the central square pyramid connects to each of the peripheral pyramids through a shared basal edge. The peripheral pyramids provide ligand-accessible coordination sites for four phosphonate or -arsonate functionalities that adopt $\mathrm{O}, \mathrm{O}^{\prime}$-syn,syn-bidentate bridging modes. The convex nature of the subunit allows the formation of capsular entities when rigid bifunctional organophosphonate ligands are employed in the reaction system. ${ }^{5 a, d}$ The stability of the $\left\{\mathrm{V}_{5} \mathrm{O}_{9}\right\}$ unit in aqueous systems not only allows the incorporation of conventional benzene-, biphenyl- or naphthyl-bisphosphonates, but it also permits the incorporation of significantly elongated ligands such as bis(4-phosphonophenyl)ethyne $\left(\mathrm{H}_{4} \mathrm{~L}^{1}\right)$ and 1,1'-bis(4-phosphonophenyl)butadiyne $\left(\mathrm{H}_{4} \mathrm{~L}^{2}\right)$, to form $\left[\mathrm{V}_{10} \mathrm{O}_{18} \mathrm{~L}_{4}^{1}\right]^{10-}$ (1) and $\left[\mathrm{V}_{10} \mathrm{O}_{18} \mathrm{~L}_{4}^{2}\right]^{10-}(2)$, which crystallise phase-pure and in good yields from the corresponding reaction systems. The two acetylenebased organophosphonate ligands were synthesised through a onepot double Sonogashira coupling reaction $\left(\mathrm{H}_{4} \mathrm{~L}^{1}\right)$ and a combination of Sonogashira and Eglinton coupling reactions $\left(\mathrm{H}_{4} \mathrm{~L}^{2}\right)$ involving diethyl-4-bromophenylphosphonate and ethynyltrimethylsilane. ${ }^{10} \mathbf{1}$ and 2 form in aqueous solution upon partial reduction of $\mathrm{NaVO}_{3}$ in the presence of the organophosphonates and $\mathrm{N}_{2} \mathrm{H}_{4}$. Despite small crystal sizes and weak diffraction patterns the single crystal X-ray diffraction analysis provided a good structural understanding of the compounds to give the constitutional assignments of $\mathrm{H}_{6} \mathrm{Na}_{6}-$ $\left[\left(\mathrm{N}_{3}\right)_{2} \supset 1\right] \cdot 42 \mathrm{H}_{2} \mathrm{O}$ and $\mathrm{H}_{6} \mathrm{Na}_{6}\left[\left(\mathrm{~N}_{3}\right)_{2} \supset 2\right] \cdot 40 \mathrm{H}_{2} \mathrm{O}$.

The compounds crystallise in the tetragonal space group $P 4 / m n c$ and their asymmetric units contain $1 / 8$ of the capsular entities with the remainder generated through symmetry operations.

The lengths of the capsular entities $\mathbf{1}$ and $\mathbf{2}$ as defined by the $\mathrm{O} \cdots \mathrm{O}$ distance of the terminal oxo ligands residing in the apical positions are 22.371(2) $\AA$ and 24.836(9) $̊$ for 1 and 2, respectively. Their inner cavities are characterised by square cuboid arrangements of the $8 \mathrm{P}$ atoms with edge dimensions of 13.202(2) $\times$ 5.568(1) $\AA^{2}$ and 15.776(6) $\times$ $5.544(1) \AA^{2}$. For both cages, the acetylene moieties bend significantly outwards whereby the average inter-planar distances between parallel aligned, opposite located phenyl rings are $c a .8 .5 \AA$. At their widest part both capsular entities have a radial diameter of $c a .8 .8 \AA$. In contrast to the smaller homologues, the incorporation of acetylene moieties now gives rise to openings at the organic side-walls of the capsules (Fig. 2). The openings in 2 have dimensions of $6.7 \times 6.1 \AA^{2}$ thus demonstrating that it is feasible to design entities that selectively incorporate or release small guests. In their pristine form, $\mathbf{1}$ and $\mathbf{2}$ encapsulate two stabilising azide ions that may act as templates during the formation of the convex capping units (closest V-N distances 3.02 and $3.06 \AA$ for $\mathbf{1}$ and 2, respectively). ${ }^{5 b, 8}$ The capsules assemble in the crystal structures to give dense lamellar packing motifs in which hydrophilic inorganic and hydrophobic organic areas are segregated. Partially hydrated sodium counterions bind to the terminal and bridging oxo ligands of the $\left\{\mathrm{V}_{5} \mathrm{O}_{9}\right\}$ units and to O-donors of the stabilising phosphonate ligands. These counterions connect the hydrophilic, inorganic ends of the molecular entities within the (001) plane; organophosphonate ligands pillar between these planes.

The results demonstrate that the capsular entities can systematically be extended (Fig. 2) and it appears plausible that even longer homologues of the rigid organophosphonate ligands can be incorporated. Limitations may arise from the poor solubility of extended ligands in the polar reaction mixtures that are required to prepare the $\left\{\mathrm{V}_{5} \mathrm{O}_{9}\right\}$ building unit.

The stability of the capsular entities $\mathbf{1}$ and $\mathbf{2}$ in $\mathrm{H}_{2} \mathrm{O}$ was demonstrated by electrospray ionisation mass spectrometry (ESI-MS, Fig. 3). A set of -4 charged species corresponding to the decavanadate cages 1 and 2 could be identified in the $m / z=500-600$ region of the spectra. For 1, the signal observed at $\mathrm{m} / \mathrm{z}=544.3$ corresponds to a $\mathrm{Na}_{2} \mathrm{H}_{2}\left[\mathrm{~V}_{4}{ }_{4} \mathrm{~V}_{6}{ }_{6} \mathrm{O}_{18}\left(\mathrm{O}_{3} \mathrm{PC}_{14} \mathrm{H}_{8} \mathrm{PO}_{3}\right)_{4}\right]^{4-}$ species. Additional signals at $m / z=534.3,538.6,549.8$ and 555.3 can be assigned to $\mathrm{H}_{8}\left[\mathrm{~V}^{\mathrm{IV}}{ }_{10} \mathrm{O}_{18}\right.$ $\left.\left(\mathrm{O}_{3} \mathrm{PC}_{14} \mathrm{H}_{8} \mathrm{PO}_{3}\right)_{4}\right]^{4-}, \quad \mathrm{NaH}_{2}\left[\mathrm{~V}^{\mathrm{V}} \mathrm{V}^{\mathrm{IV}}{ }_{5} \mathrm{O}_{18}\left(\mathrm{O}_{3} \mathrm{PC}_{14} \mathrm{H}_{8} \mathrm{PO}_{3}\right)_{4}\right]^{4-}, \quad \mathrm{Na}_{3} \mathrm{H}\left[\mathrm{V}^{\mathrm{V}}{ }_{4}^{-}\right.$ $\left.\mathrm{V}_{6}^{\mathrm{IV}} \mathrm{O}_{18}\left(\mathrm{O}_{3} \mathrm{PC}_{14} \mathrm{H}_{8} \mathrm{PO}_{3}\right)_{4}\right]^{4-}$ and $\mathrm{Na}_{4}\left[\mathrm{~V}_{4}{ }_{4} \mathrm{~V}^{\mathrm{V}}{ }_{6} \mathrm{O}_{18}\left(\mathrm{O}_{3} \mathrm{PC}_{14} \mathrm{H}_{8} \mathrm{PO}_{3}\right)_{4}\right]^{4-}$ species, respectively. Similarly, in the mass spectrum of 2 (Fig. 3), the signal at $\mathrm{m} / \mathrm{z}=573.6$ originates from $\mathrm{Na}_{3}\left[\mathrm{~V}^{\mathrm{V}}{ }_{5} \mathrm{~V}^{\mathrm{V}}{ }_{5} \mathrm{O}_{18}\right.$ $\left.\left(\mathrm{O}_{3} \mathrm{PC}_{16} \mathrm{H}_{8} \mathrm{PO}_{3}\right)_{4}\right]^{4-}$ species. Additional signals, comparable to those reported for 1, were also observed and assigned. The experimental and modelled isotopic distributions of these anionic species are 

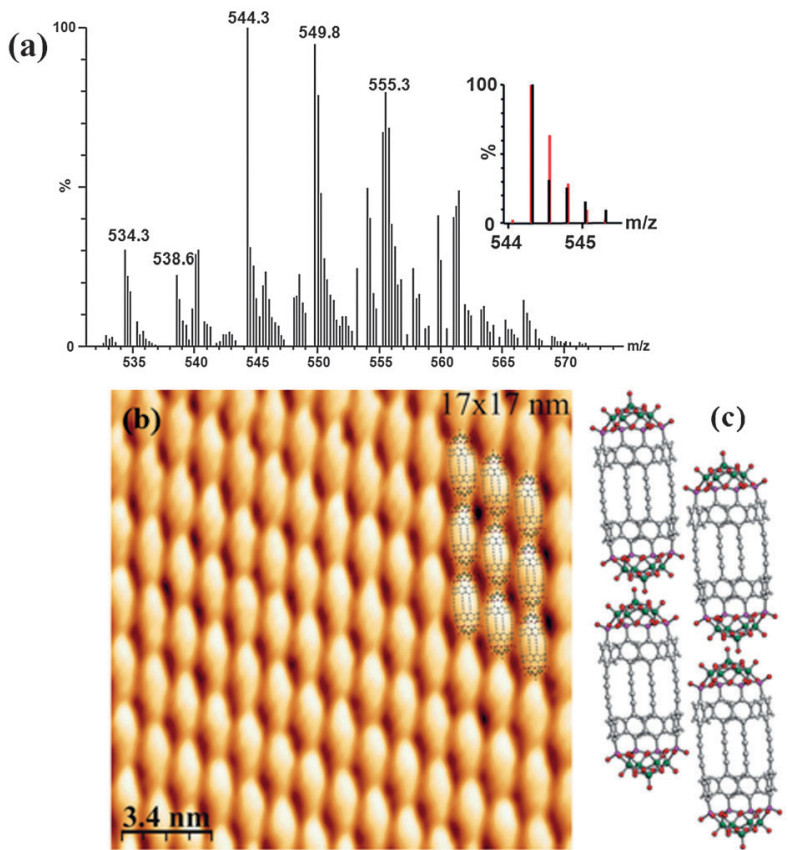

Fig. 3 (a) ESI mass spectrum of $\mathrm{H}_{6} \mathrm{Na}_{6}\left[\left(\mathrm{~N}_{3}\right)_{2} \supset 1\right] \cdot 42 \mathrm{H}_{2} \mathrm{O}$ dissolved in $\mathrm{H}_{2} \mathrm{O}$ Inset: comparison of experimental isotopic envelopes (black spectrum) with simulated patterns (red spectrum) for $\mathrm{Na}_{2} \mathrm{H}_{2}\left[\mathrm{~V}_{4}^{\mathrm{V}} \mathrm{V}^{\mathrm{IV}}{ }_{6} \mathrm{O}_{18}\left(\mathrm{O}_{3} \mathrm{PC}_{14} \mathrm{H}_{8} \mathrm{PO}_{3}\right)_{4}\right]^{4-}$ centred at $m / z=544.3$. (b) A constant current STM image of 2 deposited by spin-coating onto the $\mathrm{Au}(111)$ surface, $V_{\text {sample }}=1.4 \mathrm{~V}, I=200 \mathrm{pA}$. (c) Schematic model of $\mathbf{2}$ on the Au(111) surface.

shown in Fig. 3 and Fig. S3-S6 (ESI $\dagger$ ). The UV-vis spectra of both $\mathrm{H}_{6} \mathrm{Na}_{6}\left[\left(\mathrm{~N}_{3}\right)_{2} \supset 1\right] \cdot 42 \mathrm{H}_{2} \mathrm{O}$ and $\mathrm{H}_{6} \mathrm{Na}_{6}\left[\left(\mathrm{~N}_{3}\right)_{2} \supset 2\right] \cdot 40 \mathrm{H}_{2} \mathrm{O}$ dissolved in $\mathrm{H}_{2} \mathrm{O}$ give rise to characteristic bands at $621 \mathrm{~nm}$ with $\varepsilon=$ $518.3 \mathrm{~L} \mathrm{~mol}^{-1} \mathrm{~cm}^{-1}$ and $\varepsilon=741.9 \mathrm{~L} \mathrm{~mol}^{-1} \mathrm{~cm}^{-1}$, respectively.

The solution stability of the capsular entities in polar reaction systems can be exploited for their deposition on surfaces. For this purpose an aqueous $7.8 \times 10^{-6} \mathrm{M}$ solution of $\mathrm{H}_{6} \mathrm{Na}_{6}\left[\left(\mathrm{~N}_{3}\right)_{2} \supset 2\right]$. $40 \mathrm{H}_{2} \mathrm{O}$ was deposited by spin-coating at room temperature onto the $\mathrm{Au}(111)$ surface, which has been cleaned according to a standard literature procedure under vacuum prior to the deposition. ${ }^{11}$ STM reveals that the molecules of 2 self-assemble on the $\mathrm{Au}(111)$ surface forming well-ordered molecular domains with a characteristic closepacked oblique structure. Despite the inhomogeneous appearance of the total surface, it is indeed facile to image areas as shown in Fig. 3b where capsular entities typically cover large areas (i.e. $200 \mathrm{~nm} \times$ $200 \mathrm{~nm}$ ) and are arranged off-set to each other revealing similarity to the packing of $\mathbf{2}$ in the crystal structure when viewed in the direction of the crystallographic $a$ - or $b$-axes ( $c f$. Fig. S2, ESI $\dagger$ ). The obtained micrographs are in agreement with the presence of strong intermolecular interactions (which involve electrostatic interactions between 2 and counterions, H-bonds and $\pi-\pi$ interactions of phenyl rings) and a low diffusion barrier on this surface at room temperature, which is characteristic of low reactivity substrates such as $\mathrm{Au}^{11}$

In summary, we demonstrated that the stability of the convex $\left\{\mathrm{V}_{5} \mathrm{O}_{9}\right\}$ unit can be exploited to prepare a homologous series of capsular entities whose dimensions can be controlled by the extent of the organic ligands. Depending on the employed organophosphonate ligand, 'windows' in the side wall can be constructed which may facilitate the uptake and release of small guest molecules giving rise to catalytic activities or molecular recognition effects. ${ }^{2 c}$ The latter aspects are the subject of our current investigations. The capsular entities are stable in solution and adopt dense packing arrangements when deposited on the $\mathrm{Au}(111)$ surface.

The authors thank the Science Foundation Ireland (SFI; 06/ RFP/CHE173 and 08/IN.1/I2047) for financial support.

\section{Notes and references}

1 (a) Q.-F. Sun, J. Iwasa, D. Ogawa, Y. Ishido, S. Sato, T. Ozeki, Y. Sei, K. Yamaguchi and M. Fujita, Science, 2010, 328, 1144; (b) A. Müller, C. Beugholt, H. Bögge and M. Schmidtmann, Inorg. Chem., 2000, 39, 3112; (c) X.-J. Kong, L.-S. Long, Z. Zheng, R.-B. Huang and L.-S. Zheng, Acc. Chem. Res., 2010, 43, 201; (d) T. S. Koblenz, J. Wassenaar and J. N. H. Reek, Chem. Soc. Rev., 2008, 37, 247; (e) J. Ling, J. Qiu, G. E. Sigmon, M. Ward, J. E. S. Szymanowski and P. C. Burns, J. Am. Chem. Soc., 2010, 132, 13395; $(f)$ S. T. Zheng, J. Zhang, X. X. Li, W. H. Fang and G. Y. Yang, J. Am. Chem. Soc., 2010, 132, 15102.

2 (a) B. Olenyuk, J. A. Whiteford, A. Fechtenkotter and P. J. Stang, Nature, 1999, 398, 796; (b) S. R. Seidel and P. J. Stang, Acc. Chem. Res., 2002, 35, 972; (c) D. Fiedler, D. H. Leung, R. G. Bergman and K. N. Raymond, Acc. Chem. Res., 2005, 38, 351.

3 (a) X.-J. Kong, Y.-P. Ren, L.-S. Long, Z. Zheng, R.-B. Huang and L.-S. Zheng, J. Am. Chem. Soc., 2007, 129, 7016; (b) M. D. Pluth, R. G. Bergman and K. N. Raymond, Acc. Chem. Res., 2009, 42, 1650; (c) P. Mal, B. Breiner, K. Rissanen and J. R. Nitschke, Science, 2009, 324, 1697; (d) Y. Inokuma, T. Arai and M. Fujita, Nat. Chem., 2010, 2, 780.

4 (a) D. J. Tranchemontagne, Z. Ni, M. O'Keeffe and O. M. Yaghi, Angew. Chem., Int. Ed., 2008, 47, 5136; (b) D.-L. Long, E. Burkholder and L. Cronin, Chem. Soc. Rev., 2007, 36, 105.

5 (a) J. M. Breen and W. Schmitt, Angew. Chem., Int. Ed., 2008, 47, 6904; (b) L. Zhang and W. Schmitt, J. Am. Chem. Soc., 2011, 133, 11240; (c) J. M. Breen, L. Zhang, R. Clement and W. Schmitt, Inorg. Chem., 2012, 51, 19; (d) J. M. Breen, R. Clérac, L. Zhang, S. M. Cloonan, E. Kennedy, M. Feeney, T. McCabe, D. C. Williams and W. Schmitt, Dalton Trans., 2012, 41, 2918.

6 (a) Polyoxometalates: From Platonic Solids to Anti-Retroviral Activity, ed. M. T. Pope and A. Müller, Kluwer, Dordrecht, 1994; (b) Polyoxometalate Chemistry: From Topology via Self-Assembly to Application, ed. M. T. Pope and A. Müller, Kluwer, Dordrecht, 2001; (c) D.-L. Long, R. Tsunashima and L. Cronin, Angew. Chem., Int. Ed., 2010, 49, 1736; (d) B. Botar, P. Kögerler and C. L. Hill, J. Am. Chem. Soc., 2006, 128, 5336; (e) U. Kortz, A. Müller, J. van Slageren, J. Schnack, N. S. Dalal and M. Dressel, Coord. Chem. Rev., 2009, 253, 2315; $(f)$ A. Müller, E. Krickemeyer, H. Bögge, M. Schmidtmann and F. Peters, Angew. Chem., Int. Ed., 1998, 37, 3360.

7 (a) M. I. Khan and J. Zubieta, Angew. Chem., Int. Ed. Engl., 1994, 33, 760; (b) J. Salta, Q. Chen, Y.-D. Chang and J. Zubieta, Angew. Chem., Int. Ed. Engl., 1994, 33, 760; (c) A. Müller, K. Hovemeier, E. Krickemeyer and H. Bögge, Angew. Chem., Int. Ed. Engl., 1995, 34, 779; (d) S. Konar and A. Clearfield, Inorg. Chem., 2008, 47, 3492; (e) S. Khanra, M. Kloth, H. Mansaray, C. A. Muryn, F. Tuna, E. C. Saňudo, M. Helliwell, E. J. L. McInnes and R. E. P. Winpenny, Angew. Chem., Int. Ed., 2007, 46, 5568.

8 (a) A. Müller, Nature, 1991, 352, 115; (b) M. T. Pope, Nature, 1992, 355, 27; (c) A. Müller, H. Reuter and S. Dillinger, Angew. Chem., Int. Ed. Engl., 1995, 34, 2328; (d) P. Song, W. Guan, L. Yan, C. Liu, C. Yao and Z. Su, Dalton Trans., 2010, 39, 3706; (e) M.-M. Rohmer, J. Devémy, R. Wiest and M. Bénard, J. Am. Chem. Soc., 1996, 118, 13007; $(f)$ D. D. Heinrich, K. Folting, W. E. Streib, J. C. Huffman and G. Christou, J. Chem. Soc., Chem. Commun., 1989, 1411.

9 (a) A. Müller, R. Rohlfing, J. Döring and M. Penk, Angew. Chem., Int. Ed. Engl., 1991, 30, 588; (b) A. Müller, M. Penk, R. Rohlfing, E. Krickemeyer and J. Döring, Angew. Chem., Int. Ed. Engl., 1990, 29, 926; (c) L. Chen, F. L. Jiang, Z. Z. Lin, Y. F. Zhou, C. Y. Yue and M. C. Hong, J. Am. Chem. Soc., 2005, 127, 8588.

10 (a) R. Chinchilla and C. Najera, Chem. Rev., 2007, 107, 874; (b) D. Champbell and G. Eglinton, Org. Synth., 1973, 5, 517.

11 S. A. Krasnikov, C. M. Doyle, N. N. Sergeeva, A. B. Preobrajenski, N. A. Vinogradov, Y. N. Sergeeva, A. A. Zakharov, M. O. Senge and A. A. Cafolla, Nano Res., 2011, 4, 376. 